\title{
Synthesis of Cyclic Carbonates by Ruthenium(VI) Bis-imido Porphyrin/TBACl-Catalysed Reaction of Epoxide with $\mathrm{CO}_{2}$
}

\author{
Caterina Damiano, ${ }^{a}$ Paolo Sonzini, ${ }^{a}$ Daniela Intrieri, ${ }^{a}$ Emma Gallo. ${ }^{a *}$ \\ Dedicated to Professor Roberto Paolesse on the occasion of his 60th birthday. \\ ${ }^{a}$ Dipartimento di Chimica, Università degli Studi di Milano, Via C. Golgi 19, 20133 Milano (Italy). \\ E-mail: emma.gallo@unimi.it.
}

Received date (to be automatically inserted after your manuscript is submitted)

Accepted date (to be automatically inserted after your manuscript is accepted)

\begin{abstract}
The catalytic activity of the ruthenium(VI) bis-imido porphyrin complex/TBACl binary system in promoting the $\mathrm{CO}_{2}$ cycloaddition to epoxides forming cyclic carbonates is here reported. The system was very efficient in catalysing the conversion of differently substituted epoxides under mild experimental conditions $\left(100{ }^{\circ} \mathrm{C}\right.$ and $0.6 \mathrm{MPa}$ of $\left.\mathrm{CO}_{2}\right)$. Even if the sole $\mathrm{TBACl}$ resulted active under the optimised experimental conditions, the addition of ruthenium species was fundamental to maximising the reaction productivity both in terms of epoxide conversions and cyclic carbonate selectivities. A preliminary mechanistic study indicated a positive role of ruthenium imido nitrogen atom in activating carbon dioxide.
\end{abstract}

KEYWORDS: Homogeneous catalysis, ruthenium, cyclic carbonates, carbon dioxide, epoxides.

Correspondence to: Department of Chemistry, Università degli Studi di Milano, Via Golgi 19, 20133 Milan (Italy).e-mail: emma.gallo@unimi.it

\section{INTRODUCTION}

The increasing emission of carbon dioxide in the atmosphere, coming from anthropic activities, is responsible for many environmental issues, such as global warming [1] and ocean acidification. [2] Thus, the scientific community is currently working towards the chemical valorisation of carbon dioxide by transforming this greenhouse gas into high added-value compounds. This can determine a positive, albeit relatively small, impact on global $\mathrm{CO}_{2}$ levels. [3-5] The limited use of carbon dioxide as a renewable $\mathrm{C}_{1}$-building block in organic synthesis is due to its inherent thermodynamic stability; accordingly, a large energy input must generally be supplied for achieving the $\mathrm{CO}_{2}$ activation. In order to use $\mathrm{CO}_{2}$ as a feedstock under sustainable experimental conditions (avoiding the use of high temperatures, high $\mathrm{CO}_{2}$ pressures and extremely reactive reagents), it is imperative to take full advantage of efficient catalytic systems for promoting the $\mathrm{CO}_{2}$ conversion into fine-chemicals. [6] 
Among all the $\mathrm{CO}_{2}$-based organic transformations, the $100 \%$ atom-efficient cycloaddition of $\mathrm{CO}_{2}$ to epoxides (Scheme 1) represents a valuable strategy for obtaining cyclic carbonates, which are extensively used as solvents in chemical processes [7-9] and batteries [10] and they are also employed as useful synthetic intermediates. [11, 12]

\section{Insert Scheme 1}

Several homogeneous and heterogeneous catalytic systems mediate the formation of cyclic carbonates starting from $\mathrm{CO}_{2}$ and epoxides, and the most productive procedures require the contemporary presence of Lewis acid (M) and Lewis base $\left(\mathrm{Nu}^{-}\right)$promoters. [13-16] One of the most validated mechanistic hypothesis proposes that the first coordination of an epoxide to the Lewis acidic metal is necessary for allowing the nucleophilic attack of the Lewis base to the threemembered ring. The so-obtained compound $\mathbf{A}$ is nucleophilic enough to attack carbon dioxide and the subsequent ring closure reaction forms the desired cyclic carbonate. Both the metal catalyst and the Lewis base are restored for repeating the catalytic cycle (Scheme 2).

\section{Insert Scheme 2}

Even if $\mathrm{M}$ is generally considered the reaction "catalyst" and the Lewis base is labelled as the "co-catalyst', it is important to remember that while the Lewis acidic species is not usually active in the absence of the nucleophilic 'co-catalyst', the $\mathrm{CO}_{2}$ cycloaddition can be catalysed by the sole Lewis base. [17] The DFT study of the TBAX-catalysed transformation of propylene oxide (PO) into propylene carbonate (PC) [18] suggested that the halide anion $\mathrm{X}^{-}$is nucleophilic enough to attack the epoxide ring, thanks to the interaction of the $\mathrm{TBA}^{+}$cation with the epoxide oxygen atom. The so-formed intermediate undergoes the $\mathrm{CO}_{2}$ insertion and the desired cyclic carbonate is formed by the following ring-closing reaction. However, the presence of the $\mathrm{M}$ catalyst is usually required for applying milder experimental conditions, improving the regioselectivity and speeding up the reaction.

Both homogeneous and heterogeneous porphyrin-based catalysts were seen to be very efficient in promoting the $\mathrm{CO}_{2}$ cycloaddition to epoxide in the presence of the opportune co-catalyst (generally an ammonium salt). Regarding homogeneous systems, [19] many metal porphyrin catalysts were tested and good results were achieved by using either main group ( $\mathrm{Al}, \mathrm{Mg}, \mathrm{Sn}, \mathrm{Bi}$ ) [20-25] or transition ( $\mathrm{Cr}, \mathrm{Co}, \mathrm{Mn}, \mathrm{Ru}$ and $\mathrm{V})$ [26-31] metal derivatives. In addition, bifunctional metal catalysts were developed by inserting both Lewis acidic and nucleophilic moieties within the same molecular skeleton. Outstanding catalytic results were obtained in the presence of bifunctional metal porphyrin complexes showing an ammonium salt on the ligand periphery. [18, 32-34]

Albeit the acidic nature of the catalyst is usually necessary to maximise the reaction performance, we recently reported that the 'non-acidic' bis-imido porphyrin complex $\mathrm{Ru}(\mathrm{TPP})(\mathrm{NAr})_{2}$ (1) (TPP = dianion of tetraphenyl porphyrin, $\left.\mathrm{Ar}=3,5-\left(\mathrm{CF}_{3}\right)_{2} \mathrm{C}_{6} \mathrm{H}_{3}\right)$, in combination with a tetrabutyl ammonium salt (TBAX), promoted the oxazolidinone synthesis by the cycloaddition of $\mathrm{CO}_{2}$ to aziridines.[35] Although the reaction mechanism has not been studied in detail, preliminary results showed that the nitrogen atom of the axial imido ligand on the ruthenium centre may activate $\mathrm{CO}_{2}$ molecule. The metal centre, being coordinatively saturated, doesn't interact with aziridine.

The good results obtained prompted us to test the catalytic activity of the Ru(TPP)(NAr) $)_{2}(\mathbf{1}) / \mathrm{TBAX}$ binary system in the $\mathrm{CO}_{2}$ cycloaddition to epoxides forming cyclic carbonates. 


\section{RESULTS AND DISCUSSION}

The catalytic activity of $\mathrm{Ru}(\mathrm{TPP})(\mathrm{NAr})_{2}(\mathbf{1})$ was first compared to that of other ruthenium complexes in the synthesis of cyclic carbonate 2. Obtained data are reported in Table 1.

\section{Insert Table 1}

As shown in Table 1, the reaction occurred in the presence of $\mathrm{TBACl}$ alone and $74 \%$ of the starting epoxide was converted and the desired cyclic carbonate 2 was formed with $62 \%$ of selectivity after 8 hours at $100{ }^{\circ} \mathrm{C}$ under $0.6 \mathrm{MPa}$ of $\mathrm{CO}_{2}$ (Table 1, entry 1). The catalytic performance improved upon adding a ruthenium species to the catalytic reaction; when $\mathrm{Ru}(\mathrm{TPP}) \mathrm{CO} / \mathrm{TBACl}$ system was used in the ratio reported in Table 1 (entry 2), the conversion increased from $74 \%$ to $77 \%$ and the cyclic carbonate selectivity from $62 \%$ to $99 \%$. The epoxide conversion was further improved to $100 \%$ by replacing $\mathrm{Ru}(\mathrm{TPP}) \mathrm{CO}$ with $\mathrm{Ru}(\mathrm{TPP})(\mathrm{NAr})_{2}(\mathbf{1})$, which mediated the formation of the desired product 2 with $99 \%$ of reaction selectivity. The compared systems mediated the synthesis of 2 by different mechanisms, which involve the sole TBACl containing both nucleophilic $\left(\mathrm{Cl}^{-}\right)$and electrophilic $\left(\mathrm{TBA}^{+}\right)$components (Table 1, entry 1) or the Lewis $\mathrm{acid} / \mathrm{base}$ system as in the case of $\mathrm{Ru}(\mathrm{TPP}) \mathrm{CO} / \mathrm{TBACl}$ combination (Table 1, entry 2 ). The beneficial effect of catalyst 1 (Table 1, entry 3 ) on the reaction productivity indicated the occurrence of a reaction mechanism in which the presence of a coordinatively unsaturated and 'acidic' metal centre is not required. In fact, the presence of the two imido axial ligands on the ruthenium atom doesn't allow the coordination, and consequent epoxide activation, onto the central metal.

The chemical stability of the catalytic $\mathrm{Ru}(\mathrm{TPP})(\mathrm{NAr})_{2}(\mathbf{1}) / \mathrm{TBACl}$ system, under the experimental conditions employed, was tested to investigate the recyclability of the catalyst. The synthesis of cyclic carbonate $\mathbf{2}$ was performed three consecutive times by adding the suitable amount of epoxide, after each complete consumption, to the initial catalytic mixture. As shown in entry 4 of Table 1, the catalytic performance was completely maintained indicating the lack of decomposition processes of the employed catalyst. Next, in order to investigate a possible scale-up of the $\mathrm{Ru}(\mathrm{TPP})(\mathrm{NAr})_{2}$ (1)/TBACl-mediated procedure, the synthesis of 2 was executed by using $1.0 \mathrm{~g}$ of the starting epoxide (Table 1, entry 5). We were delighted to observe a complete retention of the reaction productivity, which paves the way to some practical applications of the procedure.

While the reaction efficiency was completely maintained when the catalyst $\mathrm{Ru}(\mathrm{TPP})(\mathrm{NAr})_{2}$ (1) was replaced by $\mathrm{Ru}(\mathrm{TPP})\left(\mathrm{NAr}^{\prime}\right)_{2}(3) \quad\left(\mathrm{Ar}{ }^{\prime}=3,5-\left(\mathrm{NO}_{2}\right)_{2} \mathrm{C}_{6} \mathrm{H}_{3}\right)$ (Table 1, entry 6), a slight decrease of the epoxide conversion was observed when more sterically encumbered porphyrin ligands were employed. In fact, the complete conversion of the epoxide was not achieved regardless of the electronic characteristics of the porphyrin ring. However, the very high epoxide conversions of $93 \%$ and $95 \%$ were obtained in the presence of $\operatorname{Ru}\left(\mathrm{F}_{20} \mathrm{TPP}\right)(\mathrm{NAr})_{2}(4)\left(\mathrm{F}_{20} \mathrm{TPP}=\right.$ dianion of tetrapentafluorophenyl porphyrin) (Table 1 entry 5) and $\mathrm{Ru}(\mathrm{TMP})(\mathrm{NAr})_{2}(\mathbf{5})(\mathrm{TMP}=$ dianion of tetramesityl porphyrin), respectively. This result indicated that the steric hindrance of the porphyrin skeleton is more influent than its electronic nature in determining the catalytic efficiency of the methodology.

In view of the good catalytic results achieved by using $\mathrm{Ru}(\mathrm{TPP})(\mathrm{NAr})_{2}(\mathbf{1}) / \mathrm{TBACl}$ binary system, this combination was employed for the synthesis of cyclic carbonates 6-12, which was also performed in the presence of TBACl alone to better appreciate the influence of the ruthenium porphyrin catalyst (Table 2). In order to improve the solubilisation of $\mathrm{CO}_{2}$ in the reaction medium, the reactions mediated by the sole TBACl were executed in THF where a better catalytic 
performance in the synthesis of 2 was observed. When working in THF, the epoxide conversion increased from $74 \%$ (Table 1, entry 1) to $91 \%$ (Table 2, entry 1), while the cyclic carbonate selectivity remained the same (62\% vs $63 \%)$ supporting the importance of maximising the $\mathrm{CO}_{2}$ solubility in the reaction solvent to amplify the catalytic efficiency.

Unfortunately, we were forced to replace THF with benzene, as the reaction solvent, when catalyst 1 was employed in combination with $\mathrm{TBACl}$, due to the poor chemical stability of the ruthenium species in coordinating solvents, such as THF. As shown in Table 2, even if the catalytic performances were always maximised by adding $\operatorname{Ru}(\mathrm{TPP})(\mathrm{NAr})_{2}(\mathbf{1})$, the positive effect was strongly related to the nature of the starting epoxide. When epoxide was mono-substituted with a $-\mathrm{CH}_{2}(\mathrm{EWD})$ group (Table 2, entries 1-3), the reaction worked well both in the presence of $\mathrm{TBACl}$ and $\mathrm{Ru}(\mathrm{TPP})(\mathrm{NAr})_{2}(\mathbf{1}) / \mathrm{TBACl}$ binary system. Compounds $\mathbf{2}$ (Table 2, entry 1), $\mathbf{6}$ (Table 2, entry 2) and 7 (Table 2, entry 3 ) were obtained with the complete conversion of the starting epoxide and with very high similar selectivities (94\% - 99\%) in the presence of the $\mathrm{Ru}(\mathrm{TPP})(\mathrm{NAr})_{2}(\mathbf{1}) / \mathrm{TBACl}$ combination.

\section{Insert Table 2}

The positive effect of the $\mathrm{Ru}(\mathrm{TPP})(\mathrm{NAr})_{2}$ (1) addition was more clearly observed in the synthesis of $\mathbf{8}$ (Table 2 , entry 4), which involved an epoxide showing an electron-donating substituent on the three-membered ring. In this case, albeit the complete epoxide conversion was observed either in the presence or in the absence of catalyst $\mathbf{1}$, the addition of the ruthenium species was responsible for an increase of the reaction selectivity from $27 \%$ to $65 \%$. Next, the catalytic influence of the steric hindrance on the epoxide ring was investigated. The presence of a phenyl substituent on the starting epoxide did not hamper the formation of the corresponding cyclic carbonate 9 (Table 2, entry 5) in good selectivities. A moderate improvement of the reaction productivity was registered by running the reaction in the presence of $\mathrm{Ru}(\mathrm{TPP})(\mathrm{NAr})_{2}(\mathbf{1}) / \mathrm{TBACl}$ instead of $\mathrm{TBACl}$ alone. When more sterically encumbered substrates were employed, the effect of the ruthenium catalyst was less evident. The synthesis of compound $\mathbf{1 0}$ (Table 1, entry 6) occurred with low selectivities both in the presence or absence of $\mathbf{1}$, due to the presence of a tetra-substituted carbon atom on the epoxide ring. The addition of $\mathrm{Ru}(\mathrm{TPP})(\mathrm{NAr})_{2}(\mathbf{1})$ did not promote the formation of the desired compound in an acceptable amount. It should be noted that the epoxide conversion was not determined in this case because its low boiling point favoured the complete elimination of the reagent during the work-up, which was executed in order to perform the NMR analysis of the crude. Very modest catalytic results were also observed in the synthesis of cyclic carbonate 11 (Table 1, entry 7) where the epoxide was converted in a very low extent in both cases. In spite of the small amount of the converted epoxide, a 99\% of the cyclic carbonate selectivity was obtained by using both the catalytic procedures. Finally, the low yield in which cyclic carbonate $\mathbf{1 2}$ was obtained could be due to the pronounced attitude of 7-oxabicyclo[4.1.0]heptane reacting with $\mathrm{CO}_{2}$ forming poly(cyclohexene carbonate) alongside the corresponding cyclic carbonate.

As reported in the Introduction, $\mathrm{Ru}(\mathrm{TPP})(\mathrm{NAr})_{2}(\mathbf{1}) / \mathrm{TBACl}$ binary system also mediated the $\mathrm{CO}_{2}$ cycloaddition to aziridines, thus a competitive experiment was performed to assess which, between epoxides and aziridines, can be better activated by this catalytic system. The reaction was performed by reacting equimolar amounts of styrene oxide and 1-butyl-2-phenyl aziridine with $\mathrm{CO}_{2}$ under the experimental conditions reported in Table 2. The NMR analysis of the crude after 8 hours revealed the lower reactivity of aziridine with respect to that of epoxide. In fact, while epoxide was completely converted into corresponding cyclic carbonate 9 , only $21 \%$ of the aziridine conversion occurred to form corresponding $N$-butyl oxazolidinone $\mathbf{1 3}$ with $99 \%$ of selectivity (Scheme 3 ). 


\section{Insert Scheme 3}

In order to better clarify the role of $\mathrm{Ru}(\mathrm{TPP})(\mathrm{NAr})_{2}$ in the catalytic reaction, some experiments were executed. In our previously published paper on the $\mathrm{CO}_{2}$ cycloaddition to aziridines catalysed by $\mathrm{Ru}(\mathrm{TPP})(\mathrm{NAr})_{2}(\mathbf{1}) / \mathrm{TBACl}$ binary system, we reported the formation of the deactivated $\mathrm{Ru}(\mathrm{TPP})(\mathrm{NAr})\left(\mathrm{ArNCOO}^{-} \mathrm{TBA}^{+}\right.$) complex (14) at the end of the catalytic reaction. [35] The formation of this latter complex indicated that the imido axial ligand on the ruthenium atom was able to interact with $\mathrm{CO}_{2}$ thanks to the high electron density on the nitrogen atom, as already indicated by our previous DFT study. [36]

The formation of complex 14 was also detected by ESI-MS at the end of the catalytic reaction forming cyclic carbonate 2. Analogously to what was observed in the case of the oxazolidinone synthesis, [35] ruthenium complex 14 was catalytically inactive when used in combination with $\mathrm{TBACl}$ for promoting the synthesis of $\mathbf{2}$, which was formed with the same conversion and selectivity values as achieved in the presence of TBACl alone (see Table 1, entry 1). In view of the formation of $\mathbf{1 4}$, a positive interaction between $\mathrm{Ru}(\mathrm{TPP})(\mathrm{NAr})_{2}(\mathbf{1})$ and $\mathrm{CO}_{2}$ was again supposed and it may be responsible for the formation of the putative $\mathrm{CO}_{2} / \mathbf{1}$ adduct $\mathbf{A}$ (Scheme 4). While the formation of intermediate $\mathbf{A}$ should represent the first step of the cyclic carbonate formation in the presence of the epoxide (path a, Scheme 4), it could be responsible for the formation of the inactive compound $\mathbf{1 4}$ when the epoxide is not present in the reaction medium (path b, Scheme 4). Thus, intermediate A can either evolve during the productive catalytic cycle or be transformed into the deactivated catalytic compound 14 by a dead-end reaction.

Unfortunately, any attempt to detect the adduct $\mathbf{A}$ between $\mathrm{CO}_{2}$ and complex $\mathbf{1}$ as well as products containing chlorine atoms, which derive from the TBACl decomposition forming 14, have failed up to now. Even if the mechanism showed in Scheme 4 is not fully supported by experimental data, the isolation of compound $\mathbf{1 4}$ at the end of the catalytic reaction strongly indicated the reactivity of ruthenium imido nitrogen atoms towards carbon dioxide.

\section{Insert Scheme 4}

Considering that cyclic carbonates were also formed in the presence of $\mathrm{TBACl}$ alone and that all the reactions were carried out by using a $1 / \mathrm{TBACl}$ molar ratio of $1: 10$, it was difficult to assess the real contribute of complex 1 in catalytic reactions occurring in the presence of a TBACl excess. To shed some light on this aspect, the model reaction forming 2 was performed by using a $\mathrm{TBACl}$ defect $(\mathbf{1} / \mathrm{TBACl} /$ epoxide $=2: 1: 100)$ in order to favour the catalytic activity of 1 at the expense of the free TBACl. The reaction carried out under these conditions occurred in a higher yield (93\%) than that performed in the presence of $\mathrm{TBACl}$ alone (57\%), suggesting the active role of the ruthenium species in the catalytic cycle. It should be noted, the model reaction forming $\mathbf{2}$ didn't occur in presence of the sole ruthenium complex 1.

In the suggested mechanism, while ruthenium complex is responsible for the $\mathrm{CO}_{2}$ activation, $\mathrm{TBACl}$ is necessary for the epoxide ring-opening reaction. This proposal was supported by the lack of interaction between 2-((allyloxy)methyl)oxirane and complex 1, as pointed out by the absence of any shift of original IR signals when the two compounds were reacted in the absence of $\mathrm{CO}_{2}$. On the other hand, when 2-((allyloxy)methyl)oxirane was reacted with $\mathrm{Ru}(\mathrm{TPP}) \mathrm{CO}$, which presents a free coordinating site, the IR spectrum of the resulting solution showed the shift of 
the $\mathrm{C}=\mathrm{O}$ IR signal of $\mathrm{Ru}(\mathrm{TPP}) \mathrm{CO}$ from $1957 \mathrm{~cm}^{-1}$ to $1817 \mathrm{~cm}^{-1}$. In addition, the IR signal attributed to epoxide shifted from $1814 \mathrm{~cm}^{-1}$ to $1715 \mathrm{~cm}^{-1}$ upon its plausible coordination to the penta-coordinated ruthenium atom.

\section{EXPERIMENTAL}

\section{General}

Unless otherwise specified, all the reactions were carried out under nitrogen atmosphere employing standard Schlenk techniques and vacuum-line manipulations. All the solvents were dried by using standard procedures unless where it is specified. 3,5-Bis(trifluoromethyl)phenyl azide, [37] 3,5-bis(nitro)phenyl azide, [37] Ru(TPP)CO (TPP = dianion of tetraphenyl porphyrin), $\quad[38] \quad \mathrm{Ru}(\mathrm{TPP})(\mathrm{NAr})_{2} \quad(\mathbf{1}) \quad\left(\mathrm{Ar}=3,5-\left(\mathrm{CF}_{3}\right)_{2} \mathrm{C}_{6} \mathrm{H}_{3}\right), \quad[39] \quad \mathrm{Ru}(\mathrm{TPP})(\mathrm{NAr})_{2}$ $\left(\mathrm{Ar}{ }^{\prime}=3,5-\left(\mathrm{NO}_{2}\right)_{2} \mathrm{C}_{6} \mathrm{H}_{3}\right.$, [40] $\mathrm{Ru}\left(\mathrm{F}_{20} \mathrm{TPP}\right)(\mathrm{NAr})_{2}(4)\left(\mathrm{F}_{20} \mathrm{TPP}=\right.$ dianion of tetrapentafluorophenyl porphyrin), [35] and $\mathrm{Ru}(\mathrm{TMP})(\mathrm{NAr})_{2}$ (5) (TMP = dianion of tetramesityl porphyrin) [35] were synthesised by methods reported in literature or by using minor modifications of them. All the other starting materials were commercial products and used as received. Analytical data of cyclic carbonates 2, 6-12 [41, 42] and oxazolidinone 13 [35] were in accordance with those reported in literature. NMR spectra were recorded at room temperature either on a Bruker Avance 300-DRX, operating at $300 \mathrm{MHz}$ for ${ }^{1} \mathrm{H}$ and at $75 \mathrm{MHz}$ for ${ }^{13} \mathrm{C}$, or on a Bruker Avance 400-DRX spectrometers, operating at $400 \mathrm{MHz}$ for ${ }^{1} \mathrm{H}$ and at $100 \mathrm{MHz}$ for ${ }^{13} \mathrm{C}$. Chemical shifts (ppm) are reported relative to TMS. The ${ }^{1} \mathrm{H}$ NMR signals of the compounds described in the following were attributed by $2 \mathrm{D}$ NMR techniques. Assignments of the resonance in ${ }^{13} \mathrm{C}$ NMR were made by using the APT pulse sequence, HSQC and HMBC techniques. Infrared spectra were recorded on a Varian Scimitar FTS 1000 spectrophotometer. UV/Vis spectra were recorded on an Agilent 8453E instrument. Mass spectra were recorded in the analytical laboratories of Milan University.

\section{General catalytic procedures}

Method A: In a $100 \mathrm{~mL}$ glass liner equipped with a screw cap and glass wool, TBACl $\left(9.71 \times 10^{-5} \mathrm{~mol}\right)$ and the epoxide $\left(9.71 \times 10^{-4} \mathrm{~mol}\right)$ in a molar ratio $=10 / 100$ were dissolved in THF $(3.3 \mathrm{~mL})$. The reaction mixture was cooled with liquid nitrogen and the flask was transferred into a stainless-steel autoclave, three vacuum-nitrogen cycles were performed and $0.6 \mathrm{MPa}$ of $\mathrm{CO}_{2}$ was charged at room temperature. The autoclave was placed in a preheated oil bath at $100{ }^{\circ} \mathrm{C}$ and stirred for $8 \mathrm{~h}$, then it was cooled at room temperature and slowly vented. The solvent was evaporated to dryness and the crude was analysed by ${ }^{1} \mathrm{H}$ NMR with 2,4-dinitrotoluene as the internal standard.

Method B: the procedure illustrated for method A was employed by using the ruthenium catalyst (5.14 x $\left.10^{-6} \mathrm{~mol}\right)$, $\operatorname{TBACl}\left(5.14 \times 10^{-5} \mathrm{~mol}\right)$ and the epoxide $\left(5.14 \times 10^{-4} \mathrm{~mol}\right)$ in the molar ratio $=1 / 10 / 100$ and benzene $(3.3 \mathrm{~mL})$ as the reaction solvent.

Synthesis of 4-((allyloxy)methyl)-1,3-dioxolan-2-one (2): The epoxide 2-((allyloxy)methyl)oxirane was employed. Collected data were in accordance with those reported in literature. [41] ${ }^{1} \mathrm{H}$ NMR $\left(300 \mathrm{MHz}, \mathrm{CDCl}_{3}\right): \delta_{\mathrm{H}}, \mathrm{ppm} 6.00-$ $5.86(1 \mathrm{H}, \mathrm{m}), 5.31-5.21(2 \mathrm{H}, \mathrm{m}), 4.86-4.75(1 \mathrm{H}, \mathrm{m}), 4.50(1 \mathrm{H}, \mathrm{t}, J=8.3 \mathrm{~Hz}), 4.43-4.36(1 \mathrm{H}, \mathrm{m}), 4.07(2 \mathrm{H}, \mathrm{d}, J=4.6 \mathrm{~Hz})$, $3.71-3.59(2 \mathrm{H}, \mathrm{m})$.

Synthesis of 4-(phenoxymethyl)-1,3-dioxolan-2-one (6): The epoxide 2-(phenoxymethyl)oxirane was employed. Collected data were in accordance with those reported in literature. [42] ${ }^{1} \mathrm{H}$ NMR $\left(300 \mathrm{MHz}, \mathrm{CDCl}_{3}\right): \delta_{\mathrm{H}}, \mathrm{ppm} 7.30$ $(2 \mathrm{H}, \mathrm{t}, J=8.3 \mathrm{~Hz}), 7.01(1 \mathrm{H}, \mathrm{t}, J=7.3 \mathrm{~Hz}), 6.92(2 \mathrm{H}, \mathrm{d}, J=7.9 \mathrm{~Hz}), 5.06-4.99(1 \mathrm{H}, \mathrm{m}), 4.64-4.58(1 \mathrm{H}, \mathrm{m}), 4.54-4.50$ 
$(1 \mathrm{H}, \mathrm{m}), 4.28-4.09(2 \mathrm{H}, \mathrm{m})$.

Synthesis of 4-(chloromethyl)-1,3-dioxolan-2-one (7): The epoxide 2-(chloromethyl)oxirane was employed. Collected data were in accordance with those reported in literature. [42] ${ }^{1} \mathrm{H} \mathrm{NMR}\left(400 \mathrm{MHz}, \mathrm{CDCl}_{3}\right): \delta, \mathrm{ppm}_{5.09-4.89}$ $(1 \mathrm{H}, \mathrm{m}), 4.61(1 \mathrm{H}, \mathrm{t}, J=8.5 \mathrm{~Hz}), 4.45-4.38(1 \mathrm{H}, \mathrm{m}), 3.75(2 \mathrm{H}, \mathrm{d}, J=5.1)$.

Synthesis of 4-ethyl-1,3-dioxolan-2-one (8): The epoxide 2-ethyloxirane was employed. Collected data were in accordance with those reported in literature. [41] ${ }^{1} \mathrm{H} \mathrm{NMR}\left(400 \mathrm{MHz}, \mathrm{CDCl}_{3}\right): \delta, \mathrm{ppm} 4.66-4.60(1 \mathrm{H}, \mathrm{m}), 4.46(1 \mathrm{H}, \mathrm{t}$, $J=8.2 \mathrm{~Hz}), 3.98(1 \mathrm{H}, \mathrm{t}, J=8.0 \mathrm{~Hz}), 1.60-1.66(2 \mathrm{H}, \mathrm{m}), 0.97(3 \mathrm{H}, \mathrm{t}, J=7.4 \mathrm{~Hz})$.

Synthesis of 4-phenyl-1,3-dioxolan-2-one (9): The epoxide 2-phenyloxirane was employed. Collected data were in accordance with those reported in literature. [42] ${ }^{1} \mathrm{H}$ NMR $\left(300 \mathrm{MHz}, \mathrm{CDCl}_{3}\right): \delta$, ppm 7.47-7.34 (5H, m), $5.67(1 \mathrm{H}, \mathrm{t}$, $J=8.0 \mathrm{~Hz}), 4.79(1 \mathrm{H}, \mathrm{t}, J=8.4 \mathrm{~Hz}), 4.33(1 \mathrm{H}, \mathrm{t}, J=8.0 \mathrm{~Hz})$.

Synthesis of 4,4-dimethyl-1,3-dioxolan-2-one (10): The epoxide 2,2-dimethyloxirane was employed. Collected data were in accordance with those reported in literature. [41] ${ }^{1} \mathrm{H} \mathrm{NMR}\left(400 \mathrm{MHz}, \mathrm{CDCl}_{3}\right): \delta, \mathrm{ppm} 4.13(2 \mathrm{H}, \mathrm{s}), 1.91(6 \mathrm{H}$, S).

Synthesis of 4,5-diphenyl-1,3-dioxolan-2-one (11): The epoxide 2,3-diphenyloxirane was employed. Collected data were in accordance with those reported in literature. [41] ${ }^{1} \mathrm{H}$ NMR $\left(300 \mathrm{MHz}, \mathrm{CDCl}_{3}\right)$ : $\delta, \mathrm{ppm} 7.51-7.45(6 \mathrm{H}, \mathrm{m}), 7.35-$ $7.36(4 \mathrm{H}, \mathrm{m}), 5.44(2 \mathrm{H}, \mathrm{s})$.

Synthesis of hexahydrobenzo[d][1,3]dioxol-2-one (12): The epoxide 7-oxabicyclo[4.1.0]heptane was employed. Collected data were in accordance with those reported in literature. [41] ${ }^{1} \mathrm{H}$ NMR $\left(400 \mathrm{MHz}, \mathrm{CDCl}_{3}\right): \delta, \mathrm{ppm}_{4.69-4.64}$ (2H, m), 1.91-1.79 (2H, m), 1.72-1.50 (4H, m), 1.48-1.33 (2H, m).

Recycle of Ru(TPP)(NAr) $)_{2}$ (1)/TBACl. Method B was followed by using 2-((allyloxy)methyl)oxirane as the reagent. After the consumption of epoxide, which was monitored by TLC analysis ( $n$-hexane/AcOEt = 8:2), 2-((allyloxy)methyl)oxirane was added again to the catalytic mixture for two more consecutive times. The ${ }^{1} \mathrm{H}$ NMR analysis of the crude revealed $99 \%$ of global yield of compound 2 .

Scale-up of the cyclic carbonate 2 synthesis. The catalytic procedure was followed by using $\operatorname{Ru}(\mathrm{TPP})(\mathrm{NAr})_{2}(\mathbf{1})(1.72$ x $\left.10^{-6} \mathrm{~mol}\right), \mathrm{TBACl}\left(8.76 \times 10^{-4} \mathrm{~mol}\right)$ and $2-(($ allyloxy$)$ methyl $)$ oxirane as the epoxide reagent $\left(1.0 \mathrm{~g}, 8.76 \times 10^{-3} \mathrm{~mol}\right) \mathrm{in}$ the molar ratio $\mathbf{1} / \mathrm{TBACl} /$ epoxide $=1 / 10 / 100$ and benzene $(25.0 \mathrm{~mL})$ as the reaction solvent. Compound 2 was obtained with $99 \%$ yield.

Comparison of the reactivity of 2-((allyloxy)methyl)oxirane and 1-butyl-2-phenilaziridine towards $\mathrm{CO}_{2}$ in the presence of 1/TBACI system.

The catalytic procedure was followed by using $\mathrm{Ru}(\mathrm{TPP})(\mathrm{NAr})_{2}(\mathbf{1})\left(1.72 \times 10^{-6} \mathrm{~mol}\right), \mathrm{TBACl}\left(1.72 \times 10^{-5} \mathrm{~mol}\right)$ and an equimolar amount of 1-butyl-phenyl aziridine $\left(1.72 \times 10^{-4} \mathrm{~mol}\right)$ and 2-phenyloxirane $\left(1.72 \times 10^{-4}\right.$ mol $)$ as the reagents in $1.1 \mathrm{~mL}$ of benzene. The NMR analysis of the crude revealed the formation of $\mathbf{9}$ (99\% yield) and $\mathbf{1 3}$ (21\% yield) and collected analytical data of 9 [42] and 13 [35] were in accordance with those reported in literature.

Synthesis of 3-butyl-5-pheniloxazalidin-2-one (13): Collected data are in accordance with those reported in literature.[35] ${ }^{1} \mathrm{H}$ NMR (300 MHz, $\left.\mathrm{CDCl}_{3}\right)$ : $\delta$, ppm 0.94 (t, $\left.J=7.2 \mathrm{~Hz}, 3 \mathrm{H}\right), 1.31-140$ (2H, m), 1.51-1.58 (2H, m), 3.23$3.38(2 \mathrm{H}, \mathrm{m}) 3.43(1 \mathrm{H}, \mathrm{t}, J=8.0 \mathrm{~Hz}), 3.92(1 \mathrm{H}, \mathrm{t}, J=8.8 \mathrm{~Hz}), 5.49(1 \mathrm{H}, \mathrm{t}, J=8.0 \mathrm{~Hz}), 7.28-7.42(5 \mathrm{H}, \mathrm{m})$.

Study of the interaction between 2-((allyloxy)methyl)oxirane and Ru(TPP)CO by IR spectroscopy. $24 \mu \mathrm{L}$ of 
2-((allyloxy)methyl)oxirane $\left(2.03 \times 10^{-4} \mathrm{~mol}\right)$ in benzene, showing the characteristic IR signal at $1814 \mathrm{~cm}^{-1}$, was added to a benzene $(0.3 \mathrm{~mL})$ solution of $\mathrm{Ru}(\mathrm{TPP})(\mathrm{CO})\left(15.0 \mathrm{mg}, 2.03 \times 10^{-5} \mathrm{~mol}\right)$, showing the characteristic IR signal at 1957 $\mathrm{cm}^{-1}$. The IR spectrum of the resulting solution displayed two new signals at $1715 \mathrm{~cm}^{-1}$ and $1817 \mathrm{~cm}^{-1}$ as well as the absence of signals at $1814 \mathrm{~cm}^{-1}$ and $1957 \mathrm{~cm}^{-1}$.

Study of the interaction between 2-((allyloxy)methyl)oxirane and Ru(TPP)(NAr) 2 (1) by IR spectroscopy. The analogous reaction was performed by using $\mathrm{Ru}(\mathrm{TPP})(\mathrm{NAr})_{2}$ (1) (IR signal at $1485 \mathrm{~cm}^{-1}$ ). No shifts were observed upon the epoxide addition.

\section{CONCLUSIONS}

In conclusion, we described the activity of the ruthenium(VI) bis-imido porphyrin complex/TBACl binary system in catalysing the synthesis of cyclic carbonates by the insertion of $\mathrm{CO}_{2}$ into the epoxide ring. Under the optimised experimental conditions of $0.6 \mathrm{CO}_{2} \mathrm{MPa}$ and $100^{\circ} \mathrm{C}$, the activity of $\mathrm{TBACl}$ was enhanced by the addition of the ruthenium species, which was fundamental for maximising both the epoxide conversion and the cyclic carbonate selectivity. The catalytic system was effective for the $\mathrm{CO}_{2}$ cycloaddition to differently substituted epoxides, which were completely transformed into corresponding cyclic carbonates displaying a low steric hindrance on the ring. The chemical stability of the catalytic system allowed its efficient recyclability, as proven by the reuse of the binary system for three consecutive times. In addition, the reaction scale-up was also carried out by transforming $1.00 \mathrm{~g}$ of starting 2-((allyloxy)methyl)oxirane into cyclic carbonate 2 (99\% yield). Obtained data indicated that the presence of a Lewis acidic transition metal catalyst is not always required and that the coordinatively saturated and 'non-acid' ruthenium(VI) bis-imido porphyrin species probably activates $\mathrm{CO}_{2}$ instead of epoxide, conversely to what is usually proposed for transition metal-catalysed cyclic carbonate syntheses. This hypothesis can open the door to several applications of $\mathrm{Ru}$ (porphyrin)(NAr) ${ }_{2}$-based catalytic systems where $\mathrm{CO}_{2}$ can be activated in other carbon dioxide valorisation processes.

Finally, the good performances of TBACl alone indicated that, in order to really evaluate the catalytic activity of a transition metal catalyst, the blank reaction must always be carried out for all the tested substrates by using the same experimental conditions applied for the catalytic species under investigation.

\section{REFERENCES}

(1) He M, Sun Y and Han B. Angew Chem Int Ed 2013; 52: 9620-9633.

(2) Kim JY, Kang DJ, Lee T and Kim KR. Biogeosciences 2014; 11: 2443-2454.

(3) Aresta M, Dibenedetto A and Angelini A. Chem Rev 2014; 114: 1709-1742.

(4) Rafiee A, Rajab Khalilpour K, Milani D and Panahi M. J Environ Chem Eng 2018; 6: 5771-5794.

(5) Kleij AW, North M and Urakawa A. ChemSusChem 2017; 10: 1036-1038.

(6) Alper E and Yuksel Orhan O. Petroleum 2017; 3: 109-126.

(7) Parker HL, Sherwood J, Hunt AJ and Clark JH. ACS Sustain Chem Eng 2014; 2: 1739-1742.

(8) Lawrenson SB, Arav R and North M. Green Chem 2017; 19: 1685-1691.

(9) Lawrenson S, North M, Peigneguy F and Routledge A. Green Chem 2017; 19: 952-962. 
(10) Wei X, Xu W, Vijayakumar M, Cosimbescu L, Liu T, Sprenkle V and Wang W. Adv Mater 2014; 26: 76497653.

(11) Kumar P, Srivastava VC and Mishra IM. Catal Commun 2015; 60: 27-31.

(12) Guo W, Gónzalez-Fabra J, Bandeira NAG, Bo C and Kleij AW. Angew Chem Int Ed 2015; 54: 11686-11690.

(13) Liang J, Huang Y-B and Cao R. Coord Chem Rev 2019; 378: 32-65.

(14) Kamphuis AJ, Picchioni F and Pescarmona PP. Green Chem 2019; 21: 406-448.

(15) Shaikh RR, Pornpraprom S and D'Elia V. ACS Catal 2018; 8: 419-450.

(16) Lang X-D and He L-N. Chem Rec 2016; 16: 1337-1352.

(17) Ema T, Fukuhara K, Sakai T, Ohbo M, Bai F-Q and Hasegawa J-y. Catal Sci Technol 2015; 5: $2314-2321$.

(18) Hasegawa J-y, Miyazaki R, Maeda C and Ema T. Chem Rec 2016; 16: 2260-2267.

(19) Intrieri D, Damiano C, Sonzini P and Gallo E. J Porphyrins Phthalocyanines 2019; 23: 305-328.

(20) Bai D, Duan S, Hai L and Jing H. ChemCatChem 2012; 4: 1752-1758.

(21) Qin Y, Guo H, Sheng X, Wang X and Wang F. Green Chem 2015; 17: 2853-2858.

(22) Wang M, She Y, Zhou X and Ji H. Chin J Chem Eng 2011; 19: 446-451.

(23) Ahmadi F, Tangestaninejad S, Moghadam M, Mirkhani V, Mohammadpoor-Baltork I and Khosropour AR. Inorg Chem Commun 2011; 14: 1489-1493.

(24) Ahmadi F, Tangestaninejad S, Moghadam M, Mirkhani V, Mohammadpoor-Baltork I and Khosropour AR. Polyhedron 2012; 32: 68-72.

(25) Peng J, Geng Y, Yang H-J, He W, Wei Z, Yang J and Guo C-Y. Mol Catal 2017; 432: 37-46.

(26) Kruper WJ and Dellar DD. J Org Chem 1995; 60: 725-727.

(27) Paddock RL, Hiyama Y, McKay JM and Nguyen ST. Tetrahedron Lett 2004; 45: 2023-2026.

(28) Jin L, Jing H, Chang T, Bu X, Wang L and Liu Z. J Mol Catal A: Chem 2007; 261: 262-266.

(29) Farhadian A, Gol Afshani MB, Babaei Miyardan A, Nabid MR and Safari N. ChemistrySelect 2017; 2: 14311435.

(30) Jin L, Chang T and Jing H. Chin J Catal 2007; 28: 287-289.

(31) Bai D, Zhang Z, Wang G and Ma F. Appl Organomet Chem 2015; 29: 240-243.

(32) Maeda C, Sasaki S and Ema T. ChemCatChem 2017; 9: 946-949.

(33) Maeda C, Shimonishi J, Miyazaki R, Hasegawa J-y and Ema T. Chem Eur J 2016; 22: 6556-6563.

(34) Maeda C, Mitsuzane M and Ema T. Org Lett 2019; 21: 1853-1856.

(35) Carminati D, Gallo E, Damiano C, Caselli A and Intrieri D. Eur J Inorg Chem 2018: 5258-5262.

(36) Manca G, Gallo E, Intrieri D and Mealli C. ACS Catal 2014: 823-832.

(37) Tanno M, Sueyoshi S and Kamiya S. Chem Pharm Bull 1982; 30: 3125-3132.

(38) Collman JP, Chong AO, Jameson GB, Oakley RT, Rose E, Schmittou ER and Ibers JA. J Am Chem Soc 1981; 103: $516-533$.

(39) Fantauzzi S, Gallo E, Caselli A, Ragaini F, Casati N, Macchi P and Cenini S. Chem Commun 2009: $3952-3954$.

(40) Smieja JA, Shirzad K, Roy M, Kittilstved K and Twamley B. Inorg Chim Acta 2002; 335: 141-146.

(41) Steinbauer J, Spannenberg A and Werner T. Green Chem 2017; 19: 3769-3779.

(42) Clegg W, Harrington RW, North M and Pasquale R. Chem Eur J 2010; 16: 6828-6843. 
Table 1. Synthesis of 4-((allyloxy)methyl)-1,3-dioxolan-2-one (2) ${ }^{a}$

\begin{tabular}{clcc}
\multicolumn{1}{c}{ catalytic system } & conv. $(\%)^{b}$ & select. $(\%)^{b}$ \\
\hline entry $^{c}$ & $\mathrm{TBACl}$ & 74 & 62 \\
$2^{d}$ & $\mathrm{Ru}(\mathrm{TPP}) \mathrm{CO} / \mathrm{TBACl}$ & 77 & 99 \\
$3^{d}$ & $\mathrm{Ru}(\mathrm{TPP})(\mathrm{NAr})_{2}(\mathbf{1}) / \mathrm{TBACl}$ & 100 & 99 \\
$4^{d}$ & $\mathrm{Ru}(\mathrm{TPP})(\mathrm{NAr})_{2}(\mathbf{1}) / \mathrm{TBACl}$ & $100^{e}$ & $99^{e}$ \\
$5^{f}$ & $\mathrm{Ru}(\mathrm{TPP})(\mathrm{NAr})_{2}(\mathbf{1}) / \mathrm{TBACl}$ & 100 & 99 \\
$6^{d, g}$ & $\mathrm{Ru}(\mathrm{TPP})(\mathrm{NAr})_{2}(\mathbf{3}) / \mathrm{TBACl}$ & 100 & 99 \\
$5^{d}$ & $\mathrm{Ru}\left(\mathrm{F}_{20} \mathrm{TPP}\right)(\mathrm{NAr})_{2}(\mathbf{4}) / \mathrm{TBACl}$ & 93 & 99 \\
$6^{d}$ & $\mathrm{Ru}(\mathrm{TMP})(\mathrm{NAr})_{2}(\mathbf{5}) / \mathrm{TBACl}$ & 95 & 99
\end{tabular}

${ }^{a}$ Reactions were performed in a steel autoclave for $8.0 \mathrm{~h}$ at $100{ }^{\circ} \mathrm{C}$ and $0.6 \mathrm{MPa}$ of $\mathrm{CO}_{2}$. ${ }^{b}$ Determined by ${ }^{1} \mathrm{H}$ NMR spectroscopy using 2,4-dinitrotoluene as the internal standard (uncertainty calculation: $\pm 1 \%$ ). ${ }^{c}$ Method A was used, except benzene was the reaction solvent. ${ }^{d}$ Method B was used. ${ }^{e}$ After three consecutive reactions. ${ }^{f}$ Performed by using $1.0 \mathrm{~g}$ of starting epoxide and $\mathbf{1} / \mathrm{TBACl} /$ epoxide $=1: 10: 100 \mathrm{in}$ $25.0 \mathrm{~mL}$ of benzene. ${ }^{g} \mathrm{Ar}{ }^{\prime}=3,5-\left(\mathrm{NO}_{2}\right)_{2} \mathrm{C}_{6} \mathrm{H}_{3}$. 
Table 2. Synthesis of cyclic carbonates 2, 6-12 ${ }^{a}$

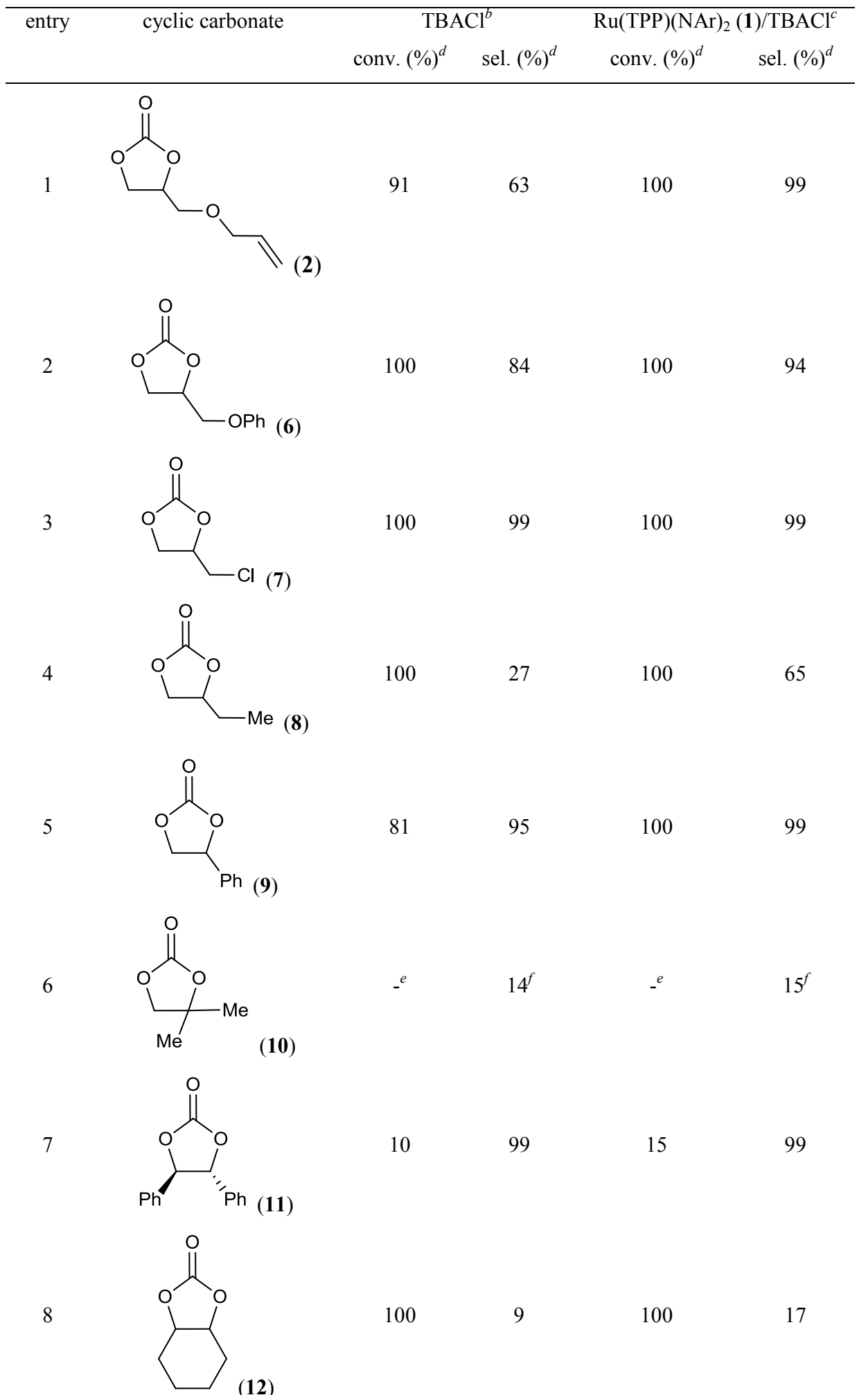

${ }^{a}$ Reactions were performed in a steel autoclave for $8.0 \mathrm{~h}$ at $100{ }^{\circ} \mathrm{C}$ and $0.6 \mathrm{MPa}$ of $\mathrm{CO}_{2}$. ${ }^{b} \mathrm{TBACl} /$ epoxide $=10: 100$ in THF. ${ }^{c} \mathbf{1} / \mathrm{TBACl} /$ epoxide $=1: 10: 100$ in benzene. ${ }^{d}$ Determined by ${ }^{1} \mathrm{H}$ NMR spectroscopy by using 2,4-dinitrotoluene as the internal standard (uncertainty calculation: $\pm 1 \%$ ). ${ }^{e}$ The selectivity was not determined because the unreacted epoxide was eliminated during the work-up due to its low boiling point. ${ }^{f}$ Yields 


$$
\stackrel{\text { [cat] }}{\longrightarrow} \overbrace{R^{1}}+\mathrm{CO}_{2}
$$

Scheme 1. General route of the cycloaddition of $\mathrm{CO}_{2}$ to epoxides forming cyclic carbonates 

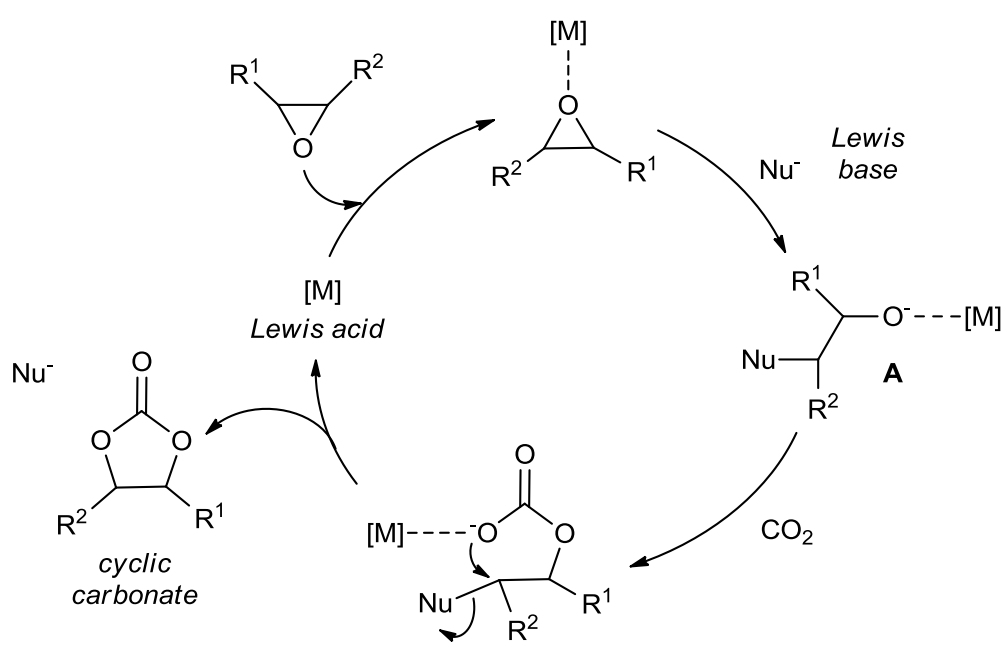

Scheme 2. Mechanistic proposal of the cyclic carbonate formation 


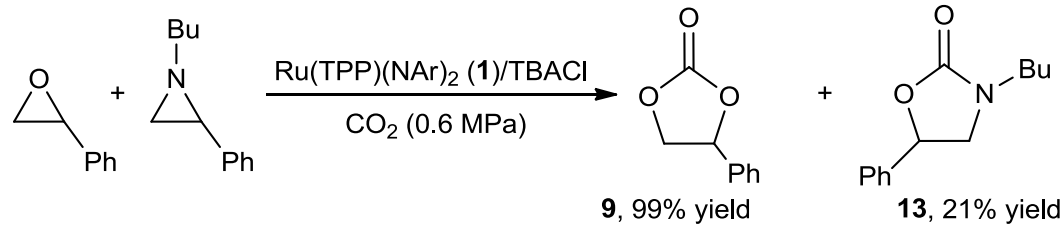

Scheme 3. Competitive cycloaddition of $\mathrm{CO}_{2}$ to an equimolar mixture of epoxide and aziridine 


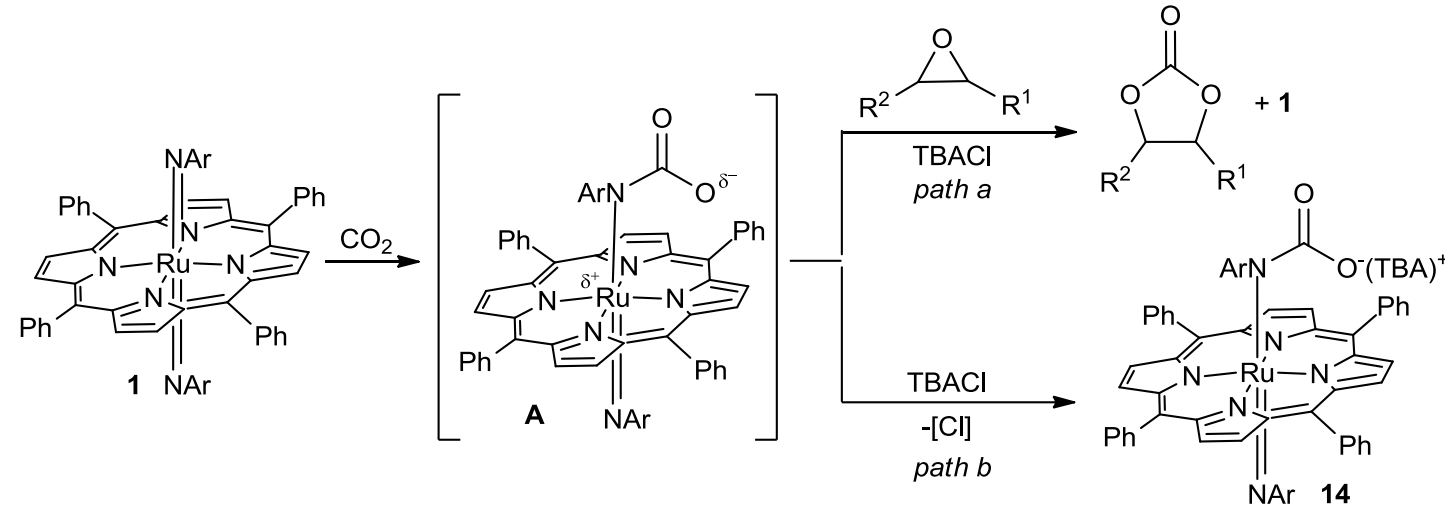

Scheme 4. Formation of complex 14 